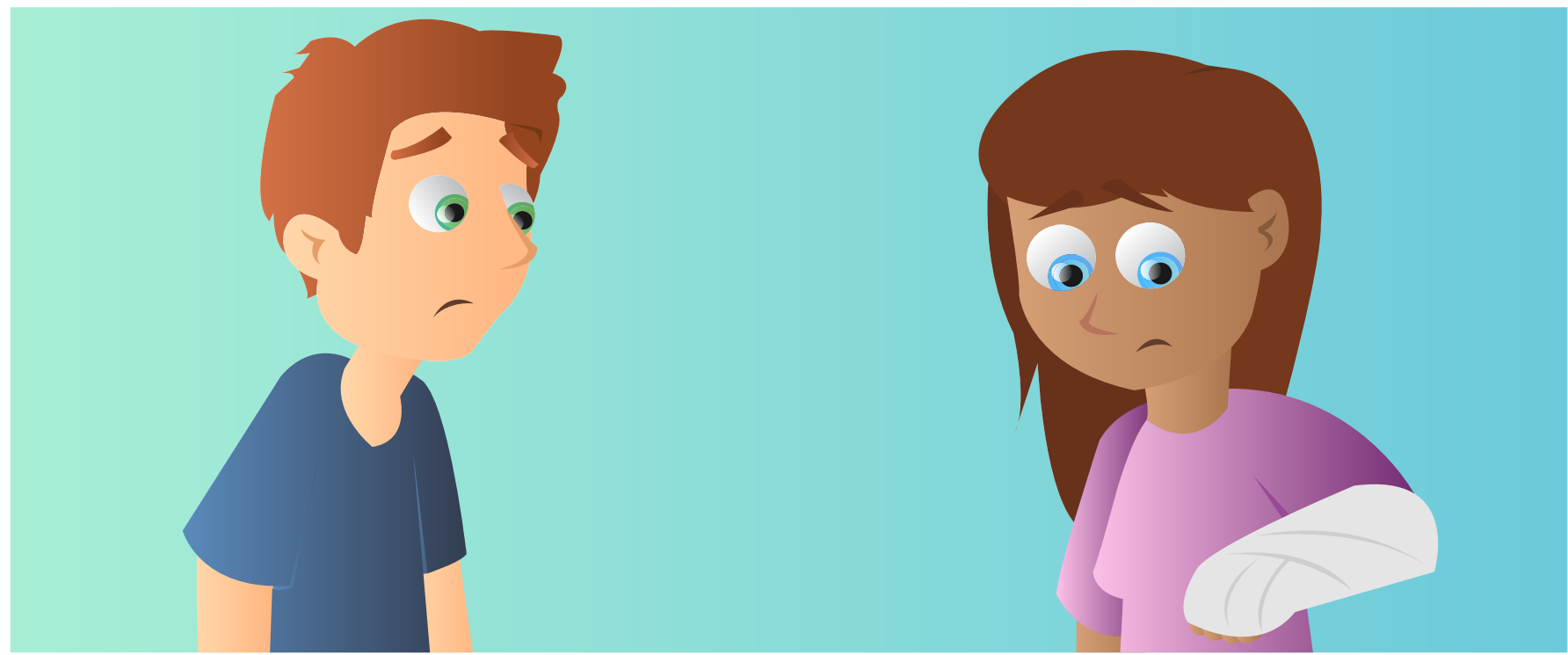

\title{
CAN TEENAGERS FEEL THE PAIN OF OTHERS? PEEKING INTO THE TEENAGE BRAIN TO FIND EMPATHY
}

\section{Jonathan Levy ${ }^{1,2 *}$ and Ruth Feldman ${ }^{1,2,3,4}$}

${ }^{1}$ Interdisciplinary Center Herzliya, Herzliya, Israel, ${ }^{2}$ Gonda Multidisciplinary Brain Research Center, Bar-Ilan University, Ramat Gan, Israel, ${ }^{3}$ Department of Psychology, Bar-llan University, Ramat Gan, Israel, ${ }^{4}$ Yale University, Child Study Center, New Haven, CT, United States

\section{REVIEWED BY:}

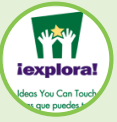

EXPLORA SCIENCE CENTER AND CHILDREN'S MUSEUM 8-15 YEARS OLD
Empathy is the ability to feel or understand the experience of another person. What happens in our brains when we feel empathy for someone who is in pain? We showed teenagers pictures of different people in pain (for example, a person who accidentally hit his knee on a hard object) and used a machine that can measure the teenagers' brains in action. The machine focused on an area in the brain that is responsible for empathy. The results showed that teenagers felt empathy toward people in pain, if those people were from the same background as the teenagers. But the teenagers felt less empathy toward people in pain who were from different backgrounds. These results are similar to the results of research on adults, which means that the empathy function in the brain is also working in teenagers. This study shows that science can be used to peek into the brains of teenagers to look at the brain activity that causes feelings of empathy in different situations. 


\section{EMPATHY}

The ability to feel or understand the experience of another person.

S1

Abbreviation for the primary somatosensory cortex, a region in the brain responsible for the sensations in the body.

\section{WHY IS FEELING EMPATHY IMPORTANT?}

Can you recall a time when a close friend of yours hurt himself? Seeing your friend in pain may have made you feel as if you yourself were in pain. When this happens, we say that you felt empathy for your friend. The feeling of empathy happens when you "put yourself in other people's shoes," and you can then understand what it feels like when someone else is happy, sad, in pain or in any other experience. So when you see your friend in pain, you may feel his pain, perhaps almost as much as your friend does.

The feeling of empathy is very important for several reasons. First, it is very important for your ability to understand others - to understand what they feel, what they want and why they act the way they do. Second, much research shows that feeling empathy motivates people to care about others and even to help each other [1]. So, empathy can really improve your interactions with your family, friends, and even with strangers. Empathy can lead people to be more caring toward each other, and more helpful. And who would not like to be around people who are caring for and helping each other?

Let us try to imagine it: for example, you see your friend hitting his knee (or any other body part) on a hard object. Now let us imagine that you do not feel empathy for him: you would just talk to him as if nothing happened; you might ask him to join you for lunch or to play a game. But in that moment, your friend is in pain and may need time and help to relieve the pain. Your friend may be upset with you because you do not understand what he is going through, and because you do not really help him in that moment when he really needs it.

But what would happen if you do feel empathy for your friend? Then, seeing your friend in pain, you would imagine feeling the same pain, almost as if you yourself hurt your knee. This would help you to understand how your friend feels in that moment. You would then come to him, ask how he feels, stay with him, and see how you can help. Of course, your friend will still feel the pain in his knee, but your caring and helping will probably make him feel better overall. This is why empathy is a very important feeling.

But how does empathy happen? Where do we feel empathy and how does it work? Well, everything we feel or do is controlled by the brain. So when you feel empathy, your brain is generating this feeling by activating certain areas of the brain that are important for empathy. Research on empathy shows that one of the major areas of the brain that is activated when you see a friend in pain is an area that scientists call S1 [2]. S1 can be seen in the red spot in the cartoon of the brain in Figure 1A. This area of the brain is not only responsible for empathy, but it is also active when you are in pain yourself. For instance, if you hit your knee, the S1 area also activates. This is very interesting, because it means that the pain you actually feel in your body may be similar to the 


\section{FIGURE 1}

Empathy inside the brain.

A. The cartoon shows one person (on the left) who is in pain after hitting his knee. This in turn triggers empathy in another person (on the right) who is watching him, and this empathy arises together with the activation of a specific brain area (see the red spot). B. Using machines such as MEG can show us this red spot in that area (called S1) on real images of the brain.

\section{PSYCHOLOGY}

The science of behavior and mind.

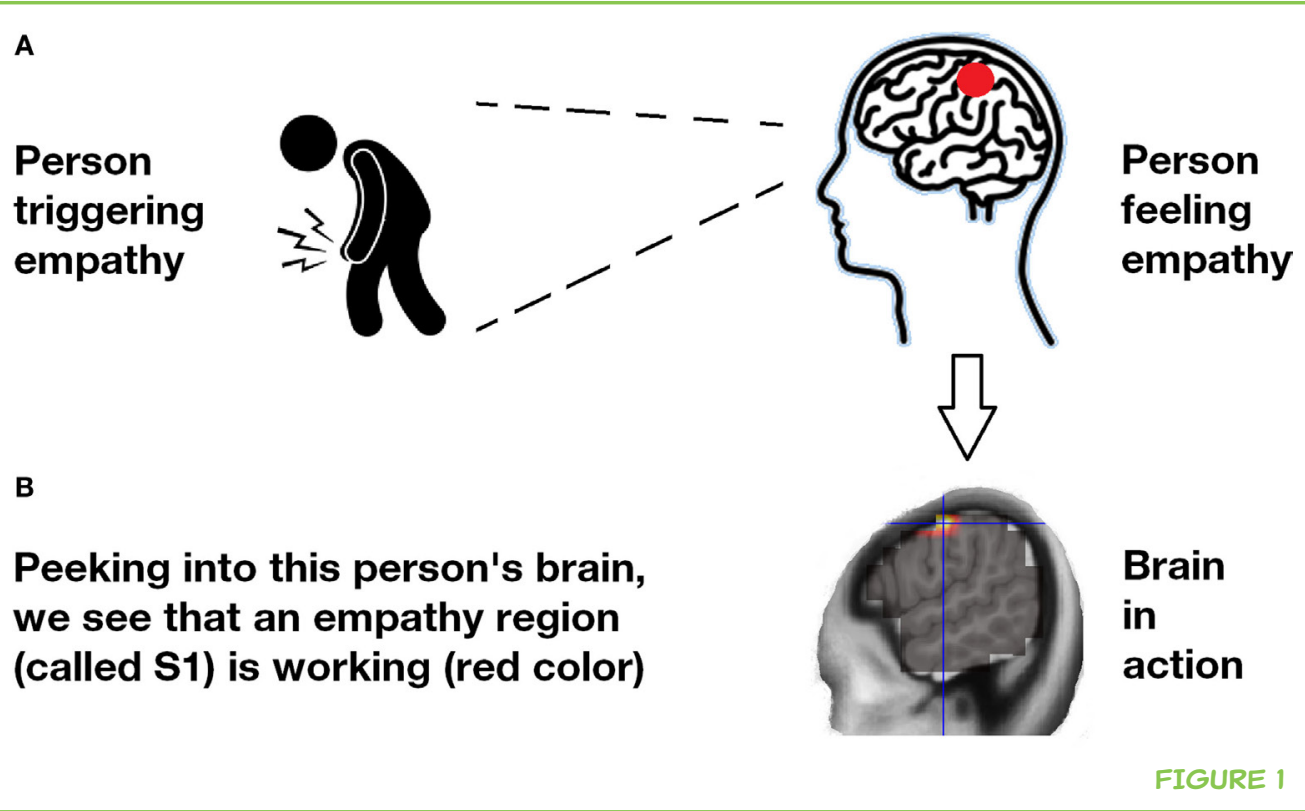

empathy you feel for a friend's pain. In other words, this may mean that when you see your friend in pain, your brain activates as if you yourself were in pain. This is why sometimes it feels painful to see someone else in pain (Figure 1A).

\section{WHEN ARE TEENAGERS MORE LIKELY TO FEEL EMPATHY?}

We have been talking about feeling empathy for a friend, but you can actually feel empathy for other people, even for strangers. We feel more empathy for some people and less empathy for others. Some explanation for the different amounts of empathy we feel comes from research in psychology, which is the science of behavior and mind. Some of this research shows that we relate differently to people who are from our own cultural background, compared with those who are not from the same background as we are [3]. In that way, we may not feel the same empathy toward everyone. This is true not only in adults, but also in children-and especially in teenagers. It is very important for teenagers to feel that they "belong" to the society or to a group of people that share the same background. Research shows that this feeling of belonging to a group makes us feel differently about those in our group compared with those outside our group. Examples of different cultures or social groups in Israel (where this research was conducted) are the Jewish and the Arab cultures. So, we thought it would be interesting to study feelings of empathy in members of these cultural groups, and in particular, to study empathy in teenagers from these two cultural groups.

But how can we know what people really feel toward each other? After all, it is difficult to tell how someone feels from the outside. But remember S1? If we can find a way to see when $S 1$ activates in the brain, we can also see if someone 
MEG

Abbreviation for magnetoencephalography, which is a machine that can map brain activity. It records the small magnetic fields produced by the electrical currents occurring naturally in the brain.

feels empathy or not. And, in fact, there is already a cool machine called MEG that is able to peek into the brain! How does MEG work? The brain is made up of billions of cells that are talking to each other. For example, when you see a picture of a dog, millions of cells in your brain talk to each other so that you can make sense of that picture. If they did not talk to each other, then you would not know that the picture shows a dog. And how do the cells talk to each other? They send an electric signal to each other. When you turn on the light switch in your room, the switch sends an electric signal to the bulb, and this turns the light on. The brain cells do something similar-they send electric signals to each other, to enable us to think, feel, and make sense of the world around us. And do you know what happens when an electric signal is sent? A small magnetic field is created, similar to what would be created by a weak magnet. Because the magnetic field created by the brain cells is very weak, we need to use MEG, which is able to measure these tiny magnetic fields when the cells talk to each other. For a detailed, kid-friendly explanation of how the MEG works, have a look at another article published in Frontiers for Young Minds [4]. After using MEG to measure the signal created by the brain cells, we can use computers to create images and colors. If the signal is strong enough, then we see a bright red spot on the area of the brain where the brain cells were talking to each other. For example, look at the red spot on the brain in Figure 1B. This means that in this area of the brain, cells were talking to each other to create empathy for the person in pain.

\section{EMPATHY INSIDE THE BRAIN}

In our study, we looked into the brains of teenagers from either the Jewish or Arab cultures, to check how much empathy they feel toward each other. We wanted to see whether teenage brains react differently toward those who belong to the same background and those who come from a different background. We invited 80 teenagers to participate in our study. We showed each teenager pictures of people in pain. For example, one picture showed a person accidently hitting her finger with a hammer; another picture showed a person accidently stepping on a nail with bare feet. Some pictures showed people from the same cultural background as the participant, and other pictures showed people from a different cultural background. To give an example of people from the same cultural background, we told the teenager that the person has the same ethnicity as they have (for instance, Jewish, if the participant is Jewish, or Arab, if the participant is Arab) and that the person lives in the same city where the participant lives, or in a nearby city. Each participant saw both types of pictures (those showing people from a similar cultural background and those showing people from a different cultural background). By using this design, our findings would be dependent on the background of the people who were feeling pain.

All of this happened inside the MEG room, with the participating teenager wearing a MEG helmet to measure his or her brain activity [4]. This experiment 


\section{FIGURE 2}

Empathy is selective.

A. Teenagers felt empathy when they watched people from a similar cultural background who were in pain. B. But when teenagers watched people from a different cultural background who were in pain, there was no empathy.

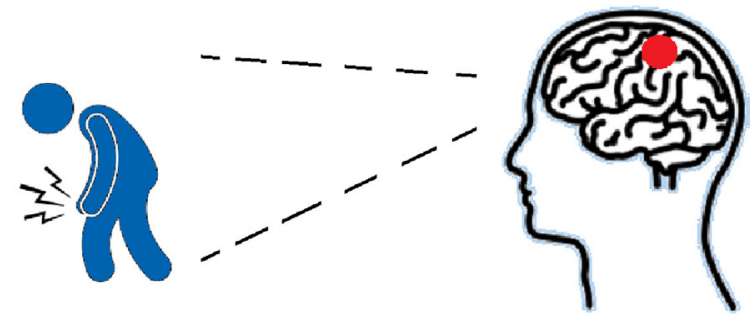

B

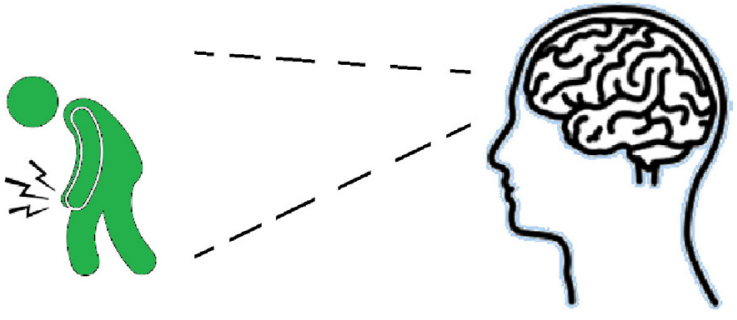

$=0$

Person

triggering

empathy
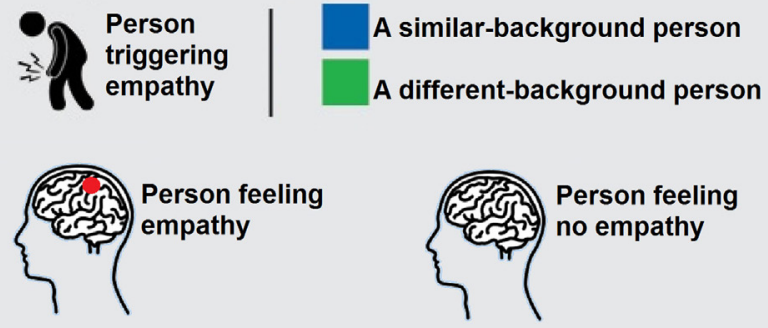

Person feeling

no empathy

was not always easy, because the teenagers had to stay inside the MEG without moving for quite a long time. MEG is a cool and comfortable machine, but it requires that the participant stay still, so that the measurement of the brain is precise. After the experiment, we looked at the MEG brain measurements of the teenagers. This allowed us to see whether they felt more empathy toward someone from their own background than toward someone from a different background.

What we found was that teenagers felt empathy when they watched people from a similar cultural background who were in pain (Figure 2A), meaning that the teenagers' brains reacted to that pain as if it had happened to them. But when teenagers watched people from a different cultural background who were in pain (Figure 2B), there was less empathy. This experiment showed us two things. First, that we can measure the brain activity of teenagers to find out whether they feel empathy or not. And second, the experiment revealed that teenagers DO feel empathy toward someone from their own background. But, they feel less empathy toward someone who does not belong to their background group. What is amazing is that we discovered all this by peeking into the teenagers' brains!

Previous research showed that this difference in the amount of empathy felt toward someone of a person's own background versus a person of a different 
background happens in adults, and here we see that it happens as early as the teenage years. This may tell us that there is an early brain mechanism responsible for "selecting" which people we feel more or less empathy for. In the future, we would like to know whether difference in empathy also happens in younger children, or even in infants. Previous psychological research reported that children prefer (i.e., feel more positive emotions toward) people from their own group, for example, from their class, school, city, nation etc. [5]. To take that study further, it would be interesting to test whether this preference also applies to empathy, and to figure out whether it is occurring in a similar or a different area of the brain.

This kind of research could be important for understanding the relationships we have with other people in our society and the attitudes we have toward people from different societies or people who belong to social groups that we do not like quite as much as our own group. As children, we may sometimes dislike kids who go to a different school or kids who are on a different sport team. As adults, we may sometimes dislike members of a company that competes against the one we work for, or again, people who support a sports team different from the one we root for. So, learning that these differences occur in our brains and that they show up early in development may help us in our daily interactions with people from other groups. We may come to understand that feeling less empathy for people who are different from us is sometimes helpful, but at other times it may create unnecessary conflicts.

In addition, studying the roots of empathy by looking at the brain can also be used in a constructive way. We could, for instance, organize social activities between teenagers from different backgrounds and use brain experiments to find out whether these activities made the teenagers feel more empathy toward each other, even toward the teenagers from a different background. Experiments like this could tell us which activities are more helpful in terms of encouraging positive interactions and emotions between people from different groups. We hope that our research will eventually have a positive effect on the way different groups get along and interact with each other.

\section{ACKNOWLEDGMENTS}

We wish to thank the collaborators on this study: Moran Influs, Abraham Goldstein, Shafiq Masalha, and Orna Zagoory-Sharon. Some icons on the figures were taken from http://thenounproject.com and slightly modified; these are under CC attribution and include the following: "Knee Pain" icon by Gan Khoon Lay, and "Human Brain" icon by Laymik. I am thankful for the use of these icons. The work was supported by grants from the Fetzer Foundation, Israel-German Foundation (1114-101.4/2010), 
the Irving B. Harris Foundation, the Simms-Mann Foundations, and the Israeli Centers of Research Excellence (i-CORE) Program of the Planning and Budgeting Committee and The Israel Science Foundation (Grant 51/11).

\section{ORIGINAL SOURCE ARTICLE}

Levy, J., Goldstein, A., Influs, M., Masalha, S., Zagoory-Sharon, O., and Ruth, F. 2016. Adolescents growing up amidst intractable conflict attenuate brain response to pain of outgroup. Proc. Natl. Acad. Sci. U.S.A. 113(48):13696-701. doi:10.1073/ pnas. 1612903113

\section{REFERENCES}

1. Batson, C. D. 2011. Altruism in Humans. New York, NY: Oxford University Press. $329 \mathrm{p}$.

2. Lamm, C., Decety, J., and Singer, T. 2011. Meta-analytic evidence for common and distinct neural networks associated with directly experienced pain and empathy for pain. Neuroimage 54:2492-502. doi:10.1016/j.neuroimage.2010.10.014

3. Tajfel, H., and Turner, J. 1979. An integrative theory of intergroup conflict. The Social Psychology of Intergroup Relations. p. 33-47. Available at: http://dtserv2. compsy.uni-jena.de/ss2009/sozpsy_uj/86956663/content.nsf/Pages/ 58BD3B477ED06679C125759B003B9COF/\$FILE/Tajfel Turner 1979.pdf

4. Brock, J., and Sowman, P. 2014. MEG for kids: listening to your brain with supercool SQUIDs. Front. Young Minds 2:1-4. doi:10.3389/frym.2014.00010

5. Bigler, R. S., and Liben, L. S. 2007. Developmental intergroup theory: explaining and reducing children's social stereotyping and prejudice. Curr. Dir. Psychol. Sci. 16:162-6. doi:10.1111/j.1467-8721.2007.00496.x

SUBMITTED: 14 May 2017; ACCEPTED: 29 September 2017;

PUBLISHED ONLINE: 27 October 2017.

EDITED BY: Kathleen Haaland, University of New Mexico, United States

CITATION: Levy J and Feldman R (2017) Can Teenagers Feel the Pain of Others? Peeking into the Teenage Brain to Find Empathy. Front. Young Minds 5:59. doi:10.3389/ frym.2017.00059

CONFLICT OF INTEREST STATEMENT: The authors declare that the research was conducted in the absence of any commercial or financial relationships that could be construed as a potential conflict of interest.

COPYRIGHT (C) 2017 Levy and Feldman. This is an open-access article distributed under the terms of the Creative Commons Attribution License (CC BY). The use, distribution or reproduction in other forums is permitted, provided the original author(s) or licensor are credited and that the original publication in this journal is cited, in accordance with accepted academic practice. No use, distribution or reproduction is permitted which does not comply with these terms. 


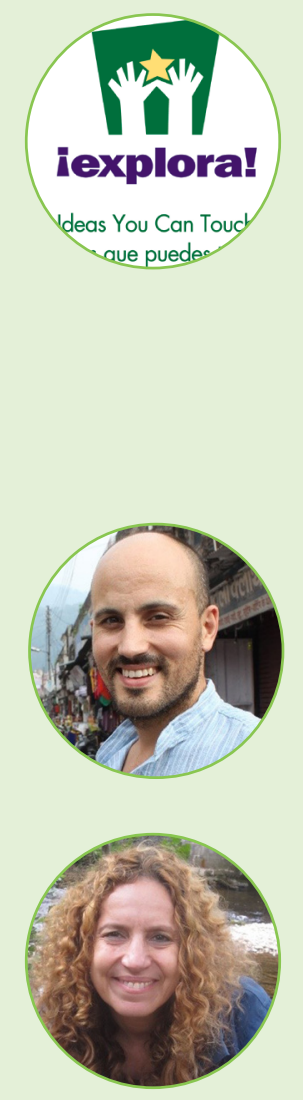

\section{REVIEWED BY}

EXPLORA SCIENCE CENTER AND CHILDREN'S MUSEUM, 8-15 YEARS OLD

The Explora Young Minds reviewers are a group of science enthusiasts working with museum educators and mentors from the University of New Mexico. We enjoy learning about the brain through the articles and hands-on activities and demonstrations. We also enjoy reading about new research, asking questions, and making suggestions to help the scientists make their work more understandable for everyone!

\section{AUTHORS}

\section{JONATHAN LEVY}

I love to study what happens in the brain when people think and feel for each other. I also like to look at situations in which these feelings and thoughts change, and to measure these changes in the brain. Beside that, I love traveling in nature, mind wandering in nature, I love India, friends, cooking, reading, yoga, resting and, playing with my kids. *yonilevy@gmail.com

\section{RUTH FELDMAN}

I am a Professor of Psychology and Neuroscience at IDC Herzliya. I studied music, clinical and developmental psychology and neuroscience in New York, in the Hebrew University of Jerusalem and in Yale University. I love to study the psychological development from being a baby till the transformation into adults. I look at how this development is sustained by the brain and hormones. I am also very interested in the parental brain and its interaction with the child brain, and I am fascinated by the hormone Oxytocin and its role in our daily interactions. Beside that, I love traveling, lecturing, yoga, and playing the piano. 